\title{
A formação de atletas de basquetebol: quantificação do tempo de prática e do número de jogos
}

\author{
CDD. 20.ed. 796.07 \\ 796.32 \\ http://dx.doi.org/10.1590/1807-55092015000400663
}

\author{
Cleiton Pereira REIS \\ Varley Teoldo da COSTA* \\ Franco NOCE* \\ Márcia Cristina Custódia FERREIRA* \\ Luiz Carlos Couto de Albuquerque MORAES*
}

\section{Resumo}

0 objetivo deste estudo foi analisar o processo de formação de atletas da categoria de base do basquetebol considerando o tempo de prática de treinamento e o número de jogos de atletas profissionais e atletas da categoria sub-19 anos de Minas Gerais. Para isso foi aplicado o Questionário sobre Tempo de Prática para Atletas de Basquetebol aos atletas e entrevistas semiestruturadas aos treinadores. Para a análise dos dados quantitativos foram aplicados os testes Shapiro-Wilk e Mann-Whitney, para um nível de significância de 5\%. Para as entrevistas, uma análise do conteúdo foi utilizada para o tratamento dos dados. Em relação à experiência competitiva, foram encontradas diferenças significativas $(p=0,003)$ que apontam um maior número de jogos disputados pelos atletas profissionais durante a sua formação na categoria de base na comparação com os atletas da categoria sub-19 anos de Minas Gerais. Conclui-se que, apesar do tempo de prática de treinamento ter sido semelhante durante o processo de formação nas categorias de base, os atletas profissionais disputaram um maior número de jogos que os atletas da categoria sub-19 anos de Minas Gerais.

Palavras-chave: Atletas; Educação física e Treinamento; Esportes; Pesquisa qualitativa.

\section{Introdução}

Avaliar os fatores que levam um indivíduo comum a se tornar um "expert" é fundamental para se entender o desempenho de excelência em determinado domínio1. "Expert" é definido por Ericsson e LEHMANN ${ }^{2}$ como um indivíduo que apresenta desempenho superior em um conjunto específico de tarefas, em um determinado domínio. Estes possuem um desempenho superior e reprodutível, ou seja, invariavelmente mantêm níveis ótimos de desempenho e devotam sua vida para alcançar o maior nível de desempenho possível ${ }^{3-5}$.

O estudo sobre a "expert performance" centra-se na análise dos indivíduos que são considerados excepcionais, que se destacam da maioria dos outros praticantes, em seus respectivos campos de atuação. O número de indivíduos considerados de excelência é menor, a partir do momento que o nível de exigência aumenta.
Dentro do ambiente esportivo considera-se como "expert" absoluto um campeão mundial ou um campeão olímpico em sua respectiva modalidade que consegue manter-se no topo por vários anos. Já o "expert" relativo pode ser definido como um indivíduo que consegue alcançar certo sucesso em sua modalidade, entretanto restringindo-se a um âmbito local, estadual e ou nacional. Outra característica que determina o "expert" relativo é que seu desempenho oscila com uma frequência maior, comparando-se com um "expert" absoluto. Em síntese a diferença entre estas duas terminologias no esporte está no fato que o "expert" absoluto atingiu o topo mais alto da pirâmide esportiva e consegue se manter neste patamar por um período de tempo mais prolongado do que o "expert" relativo ${ }^{2,3,6}$.

ERICsson et al. ${ }^{3}$ realizaram um estudo que foi um marco na investigação sobre a prática de indivíduos 
com desempenho de excelência. Participaram do estudo violinistas e pianistas alemães, e mediu-se o tempo de prática através de entrevistas biográficas. Assim foi possível saber quantas horas semanais os músicos dedicavam à prática dos instrumentos desde o início da carreira. Também foram identificadas 10 categorias de atividades que os músicos faziam diariamente além de tocar o instrumento, como: atividades de lazer, dormir, cuidados com o corpo, entre outras. Os pesquisadores constataram que os melhores violinistas acumularam mais horas de prática durante a carreira que os considerados menos qualificados, além de participarem de mais concursos musicais. Quanto aos pianistas o mesmo resultado foi encontrado, quando comparados "experts" com amadores. Os resultados deste estudo e de outras investigações no campo da "expertise" $2,4,5$ ressaltam que o tempo de prática é um dos fatores mais determinantes para que um indivíduo se torne um "expert".

Através do estudo supracitado, os autores verificaram que "experts" se dedicavam à prática de forma mais estruturada que os não "experts", pois estes indivíduos treinavam de forma individualizada sob constante supervisão de um mentor, e buscavam para a melhoria dos aspectos específicos do desempenho a repetição constante do treinamento. Este processo foi denominado "Prática Deliberada".

STARKES et al. ${ }^{7}$ buscaram estudar como se procedia a prática deliberada de indivíduos "experts" e não "experts" no meio esportivo. Para isso os pesquisadores mediram como se procedia a prática de atletas e ex-atletas canadenses de luta greco-romana de nível internacional (participantes de campeonatos mundiais e olimpíadas) e de nível regional. Em geral, os atletas de nível internacional começaram a carreira aos 13 anos de idade, e aos 16 anos começaram a treinar de forma deliberada. Aos 25 anos, os ex-atletas chegaram ao auge da carreira. Os considerados de nível internacional tiveram maior tempo dedicado aos treinamentos e às competiçóes em relação aos atletas menos qualificados. Para o estudo, os esportistas responderam um questionário no qual reportavam quantas horas em média gastavam por semana com as atividades relacionadas ou não com o treinamento, desde o começo da carreira.

O tempo de prática pode ser caracterizado de acordo com a fase de desenvolvimento do esportista. BLOOM ${ }^{8}$ e CôTÉ ${ }^{9}$ consideram que na primeira fase, ou anos de investimento, a criança precisa praticar atividades lúdicas e prazerosas, com grande apoio e cuidado de pais e professores. Nesta fase a criança deveria ingressar em vários esportes, sem ter um tempo de prática exclusivo em uma única modalidade. Depois dos 14 anos, na fase de especialização, o adolescente treinaria no máximo dois esportes, selecionado mais seu tempo de prática. Por apresentar melhores condiçóes físicas e psicológicas após os 16 anos, na fase de investimento, o atleta deveria aumentar exponencialmente o tempo de prática nos treinamentos e nas competiçôes, focando apenas em um esporte ${ }^{10}$.

O tempo de prática, nos treinamentos e competições, pode ser definido como um dos principais fatores para se avaliar o processo de formação de um indivíduo rumo ao desempenho de excelência. Sendo assim é importante avaliá-lo nas modalidades esportivas de alto rendimento. Isto tem sido feito nos estudos com atletas de esportes coletivos ${ }^{11}$, de futebol ${ }^{12}$, nadadores ${ }^{13}$, atletas de futsal ${ }^{14}$, ginástica olímpica ${ }^{15}$ e campeóes olímpicos ${ }^{16}$.

No contexto da prática de "experts" no Brasil, FerREIRA et al. ${ }^{1}$ verificaram a prática de nadadores medalhistas olímpicos brasileiros através de entrevistas semiestruturadas. Neste estudo os atletas precisaram praticar o esporte por mais de nove anos para atingirem o patamar de atletas olímpicos, e os treinamentos eram extenuantes e extremamente bem planificados. Além disso, a maior parte destes atletas foi para os Estados Unidos para ter a oportunidade de treinar e competir com os melhores atletas do mundo e também serem treinados por profissionais de excelência que dispunham de uma adequada infraestrutura para treinamentos e competiçóes, com tecnologia de ponta para a formaçáo de nadadores "experts".

Quanto ao Basquetebol, esporte objeto de pesquisa do presente estudo, pode-se destacar o trabalho de Nuno et al. ${ }^{17}$. Tais pesquisadores, ao investigar a trajetória de atletas portugueses de basquetebol através de um questionário que mede o tempo de prática, verificaram que os atletas profissionais dedicam mais horas semanais aos treinamentos e competiçóes que os atletas que não atingiram o profissionalismo. Os atletas considerados "experts" se dedicam ao treinamento e as competiçóes durante 11 meses por ano, enquanto os seus pares menos graduados durante nove meses. Como este estudo verificou também o tempo de prática de acordo com as fases de desenvolvimento, foi possível verificar que os atletas profissionais praticavam vários esportes na primeira fase de desenvolvimento. Depois dos 15 anos de idade, estes atletas priorizaram a prática do basquetebol, aumentando as horas semanais de treinamento e número de competiçóes disputadas.

De acordo com os estudos na área da "expert performance", não apenas o tempo de prática, mas 
também outras variáveis influenciam o processo de formação de um atleta "expert", tais como: o apoio dos pais e familiares aos atletas para o ingresso e permanência na prática esportiva ${ }^{9,15}$, presença de treinadores e membros da comissão técnica qualificados para elaborar e monitorar o processo de formação do atleta $^{1,15,18}$, instalaçóes esportivas e materiais adequados para o treinamento e competição, suporte financeiro para manter o atleta na modalidade esportiva ${ }^{1,4,7}$.

Porém, também ao se considerar os trabalhos desta mesma área de investigação, é pouco provável que um atleta de basquetebol consiga se tornar um "expert" da modalidade sem um adequado volume de tempo de prática e de jogos ${ }^{4,7,17}$. Quantificar estas variáveis torna-se necessário para se aperfeiçoar o processo de formação de atletas de basquetebol e também contribuir de forma significativa para otimizar o planejamento dos recursos humanos, financeiros e estruturais necessários ${ }^{7,10,18}$.

Evidências apontam para o fato de que contextos culturais e condiçôes econômicas e estruturais de desenvolvimento esportivo distintos, em uma

\section{Método}

A atual investigação se enquadra como um estudo descritivo, com característica retrospectiva, que permite a análise de práticas e percepçóes de uma populaçáo específica ${ }^{19}$. Apresenta-se uma abordagem qualitativa e quantitativa, que possibilita: a confirmação e corroboração entre os dados coletados e estabelecer-se uma visão holística acerca do fenômeno ${ }^{20}$.

Este estudo foi aprovado pelo Comitê de Ética em Pesquisa da Universidade Federal de Minas Gerais, sob o n. de protocolo 0226.0.203.000-11.

\section{Amostra}

Participaram deste estudo 94 atletas e cinco treinadores de basquetebol, ambos do sexo masculino. Sendo 47 atletas, da categoria sub19 anos que disputavam competiçóes federadas, promovidas pela Federação Mineira de Basketball (com média de idade de 18,36 $\pm 0,96$ anos) e seus respectivos treinadores (com média de idade de $36,08 \pm 11,92$ anos). Também foram avaliados 47 atletas profissionais com média de idade de $27,03 \pm 5,63$ anos, pertencentes a cinco equipes participantes da Liga Nacional de Basquetebol (NBB- Novo Basquete Brasil). determinada modalidade esportiva, influenciam o tempo de prática e de quantidade de jogos necessários para a formação dos atletas "experts",

No basquetebol, a quantificação do tempo de prática e do número de jogos justifica-se pela necessidade de mensurar e criar parâmetros científicos que possam nortear e orientar o planejamento dos treinadores que trabalham no processo de formação de atletas. Os modelos de "expert performance" de Ericsson et al. ${ }^{3}$, Ericsson e Lehmann ${ }^{2}$ e Cotê et al. ${ }^{10}$ sugerem que a parametrização destas variáveis (tempo de prática e número de jogos), associadas também ao controle das variáveis do contexto como apoio familiar, qualidade dos treinadores e da prática deliberada possibilita avançar-se em direção a uma formação esportiva de excelência.

Sendo assim, o objetivo deste estudo foi analisar o processo de formação de atletas da categoria de base do basquetebol considerando o tempo de prática de treinamento e o número de jogos de atletas profissionais e atletas da categoria sub-19 anos de Minas Gerais.

A seguir estáo explicitados os critérios para seleção da amostra: participaram do estudo os atletas e treinadores pertencentes a todas as cinco equipes da categoria sub-19 anos que disputaram as competiçóes promovidas pela Federação Mineira de Basketball na temporada 2011.

$\mathrm{Na}$ categoria profissional foram convidados a participar do estudo todos os atletas das oito equipes que se classificaram para o "play-off final" da NBB na temporada 2010-2011. Três equipes se recusaram a ceder os atletas para participar do estudo. Assim participaram deste estudo atletas de cinco equipes profissionais do NBB. Das cinco equipes que deram o aval para os atletas participarem do estudo, três terminaram nas quatro primeiras colocaçóes da temporada 2010-2011 do NBB.

Para estudos da área da "expert performance", é necessário convidar indivíduos que tenham um padrão de desempenho elevado em comparação ao resto da população, para uma tarefa específica ${ }^{2}$. Em suma, apenas aqueles mais qualificados foram convidados a participar do estudo. Outras investigaçóes na área de "expert performance" seguiram critérios semelhantes para o convite dos participantes, ou seja, escolha de uma amostra mais qualificada possível em um determinado domínio de proficiência ${ }^{1,13,15,18}$. 


\section{Instrumentos}

Questionário sobre o Tempo de Prática para Atletas de Basquetebol (QTP-Basq)

O Questionário sobre Tempo de Prática para Atletas de Basquetebol tem como aporte teórico os modelos de desenvolvimento de talentos desenvolvidos por BLOOM ${ }^{8}$ e CÔTÉ 9 e o modelo do treinador ${ }^{15}$.

$\mathrm{O}$ instrumento mensura, em cada fase de desenvolvimento do atleta na categoria de base (seis aos 13 anos, 14 aos 15 anos e 16 aos 19 anos), o volume de prática (em horas). Também avalia o número de jogos realizados anualmente por cada atleta nas fases supracitadas (ANEXO 1). Estudos com este viés qualitativo têm sido desenvolvidos em várias modalidades esportivas para avaliar o tempo de prática de atletas ${ }^{7,14,16-17}$.

\section{Entrevista semiestruturada}

A técnica de entrevista semiestruturada para a coleta de dados tem sido utilizada como uma ferramenta para entender de forma holística o processo de desenvolvimento de atletas rumo ao desempenho de excelência ${ }^{1,13}$. Este tipo de instrumento ao privilegiar a fala de atores sociais permite atingir um nível de compreensão que se torna acessível por meio de discursos, sendo apropriada para investigação cujo objetivo é conhecer como um grupo de pessoas percebe um determinado fenômeno social ${ }^{21}$.

A entrevista semiestruturada foi realizada com os treinadores federados da categoria sub-19 anos em Minas Gerais. O objetivo desta etapa do estudo foi avaliar a percepçáo dos mesmos a respeito do processo de formação dos atletas de basquetebol na categoria de base. O roteiro da entrevista semiestruturada foi elaborado tendo como principais eixos temáticos: o tempo de prática dos atletas, a qualidade desta prática esportiva e número de jogos necessários para a formação de um atleta de alto rendimento no basquetebol brasileiro.

As perguntas foram previamente listadas, mas apenas como um roteiro. Este tipo de instrumento é caracterizado pela flexibilidade, pois o pesquisador estabelece a ordem das questóes de acordo com o andamento da entrevista $^{21-22}$. Foi utilizado, para a gravação das entrevistas, um aparelho da marca Philips Digital Pocket Meno ${ }^{\circledR}$. Depois as entrevistas foram transcritas com ajuda de um pedal da marca Philips Transcription Set ${ }^{\circledR}$, que permitia o controle da gravação sem o uso das mãos.

A validaçáo dos instrumentos, tanto o conteúdo do Questionário sobre o Tempo de Prática para Atletas de Basquetebol (QTP-Basq), Versão Recursos para o Treinamento e Entrevista Semiestruturada foram feitas através da técnica de "expert rating", ao passar pela análise de cinco peritos especialistas em Psicologia do esporte e Treinadores de Basquetebol. Todos os itens avaliados tiveram a concordância dos peritos acima de $80 \%{ }^{21-23}$.

\section{Procedimentos}

A Confederação Brasileira de Basketball enviou uma carta aos pesquisadores apoiando o presente estudo. De posse de tal carta, foi feito um primeiro contato com os diretores de basquetebol das equipes da categoria sub-19 anos e profissional, para a obtenção do aval institucional para a realização do estudo. Foram agendadas datas para a coleta de dados com cada equipe. A realização do estudo aconteceu em um momento que não atrapalhou a rotina de treinamento e de jogos.

Tanto a aplicação do questionário aos atletas quanto as entrevistas com os treinadores aconteceram em um local reservado. Este local garantiu, aos indivíduos, silêncio e conforto. Os instrumentos de pesquisa foram aplicados por um único pesquisador (questionário e entrevistas), que forneceu todas as explicaçóes necessárias para o bom entendimento por parte dos sujeitos. As transcriçóes literais das entrevistas foram enviadas aos cinco treinadores da categoria sub-19 anos de Minas Gerais, juntamente com uma carta, que foi assinada e reenviada aos pesquisadores, como forma de consentimento à veracidade dos dados.

\section{Análise dos dados}

Para os dados quantitativos, foi aplicado um teste de Shapiro-Wilk para verificar a normalidade dos dados. Como todos os dados comparativos foram considerados não paramétricos, foi utilizado o teste de Mann-Whitney para a realização das comparaçôes entre as fases de desenvolvimento da formação dos atletas. O nível de significância adotado foi de $5 \%$. Todas as análises foram realizadas no programa estatístico SPSS for Windows ${ }^{\circledR}$, versão 17.0.

A análise do conteúdo das entrevistas feitas com os treinadores seguiu as diretrizes estabelecidas nos estudos de Côté et al. ${ }^{15}$, Johnson et al. ${ }^{13}$, Maciel e Moraes ${ }^{24}$, Ferreira et al. ${ }^{1}$. As entrevistas foram divididas em pequenos trechos, ou miniunidades, denominadas "meaning units" (MUs) ${ }^{25}$. Elas são consideradas as menores partes compreensíveis de um texto que expressam uma ideia ou informação. Para prevalecer o anonimato dos cinco entrevistados, cada 
MU foi identificada com a letra T (treinador), e um número de 1 a 5 . Além disso, elas foram rotuladas para a identificação do conteúdo de suas informaçóes:

\section{Resultados}

\section{Experiências competitivas}

Neste tópico é apresentado o número de jogos que os atletas da categoria sub-19 anos de MG e profissionais foram submetidos durante a categoria de base. Os dados coletados com os atletas foram confrontados com as entrevistas semiestruturadas dos treinadores com o intuito de verificar o grau de veracidade destes indicadores e também

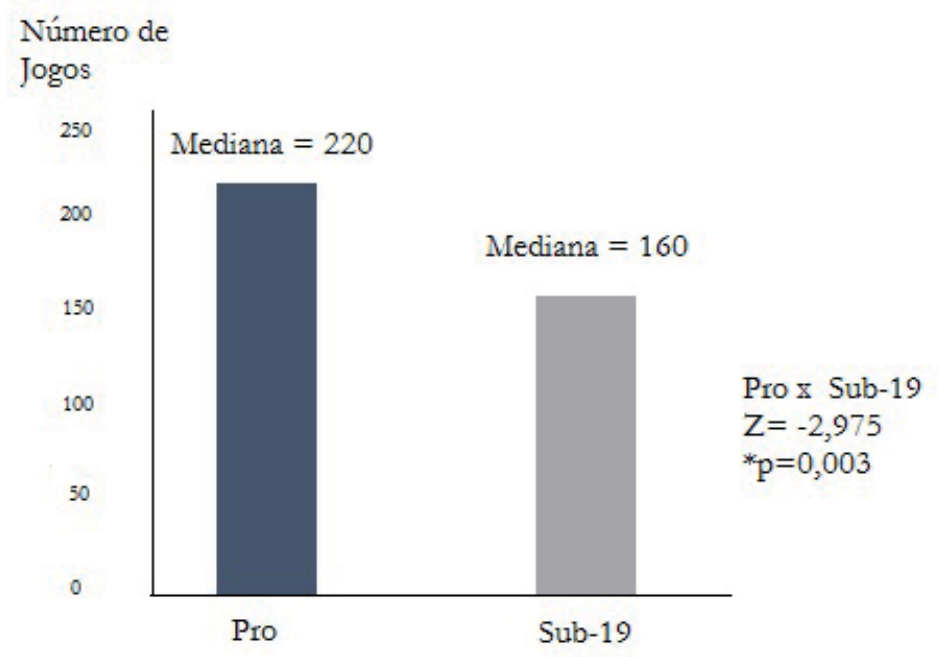

FIGURA 1 - Volume de jogos totais disputados até os 19 anos de idade pelos atletas profissionais e da categoria sub-19 anos de Minas Gerais e valores do teste de Mann-Whitney.

$\mathrm{Na}$ comparação por fases de desenvolvimento somente foi encontro diferença significativa no número de jogos entre os 16 e 19 anos, denominada fase de investimento proposta por CôTÉ ${ }^{9}$, conforme mostra a TABELA 1.
As MUs foram classificadas em três categorias: volume de prática dos atletas, qualidade da prática e avaliação do número e da qualidade das competições. contextualizar a variável tempo de experiência competitiva na formação destes atletas.

Foram encontradas diferenças significativas no número de jogos entre atletas profissionais e atletas da categoria sub-19 anos. Observa-se que os atuais atletas profissionais disputaram um número maior de jogos no período de sua formação esportiva (até os 19 anos) em relação aos atletas da categoria sub-19 anos que atualmente disputam competiçóes federadas (FIGURA 1).

TABELA 1 - Volume de jogos disputados pelos atletas profissionais e da categoria sub-19 anos de Minas Gerais por fase de desenvolvimento e valores do teste de Mann-Whitney.

\begin{tabular}{lcccc}
\hline Fase de desenvolvimento & $\begin{array}{c}\text { Pro } \\
\text { Mediana }\end{array}$ & $\begin{array}{c}\text { Sub-19 } \\
\text { Mediana }\end{array}$ & Z & Pro x sub19 \\
\hline 6-13 anos & 0 & 0 & $-1,189$ & 0,234 \\
$14-15$ anos & 40 & 36 & $-0,657$ & 0,511 \\
$16-19$ anos & 160 & 120 & $-3,855$ & $*<0,001$ \\
\hline
\end{tabular}

Pro: Atletas Profissionais;

Sub-19: Atletas da Categoria Sub-19 anos de Minas Gerais; ${ }^{*} \mathrm{p}<0,05$. nais

Sub-19: Atletas da Categoria Sub-19 anos de Minas Gerais; ${ }^{*} \mathrm{p}<0,05$. 
TABELA 2 - Volume de jogos disputados pelos atletas profissionais e da categoria sub-19 anos de Minas Gerais por fase de desenvolvimento e valores do teste de Mann-Whitney, considerando apenas os atletas que treinaram basquetebol em cada fase.

Pro: Atletas Profissio-

nais;

Sub-19: Atletas da Categoria Sub-19 anos de Minas Gerais; ${ }^{*} \mathrm{p}<0,05$.

Pro: Atletas Profissionais

Sub;-19: Atletas da Categoria Sub-19 anos de Minas Gerais.

\begin{tabular}{lcccc}
\hline Fase de desenvolvimento & $\begin{array}{c}\text { Pro } \\
\text { Mediana }\end{array}$ & $\begin{array}{c}\text { Sub-19 } \\
\text { Mediana }\end{array}$ & Z & Prox sub19 \\
\hline 6-13 anos & 75 & 60 & 0,91 & 0,924 \\
$14-15$ anos & 55 & 40 & $-1,065$ & 0,287 \\
$16-19$ anos & 160 & 120 & $-3,855$ & $*<0,001$ \\
\hline
\end{tabular}

A constatação do diminuto volume de jogos acumulados na carreira na categoria de base, que os atletas da categoria sub-19 anos de MG possuem em comparação aos atletas profissionais, conforme mostrou os dados quantitativos, corrobora com os dados coletados nas entrevistas com os treinadores. $\mathrm{O}$ principal motivo relatado é a pequena quantidade de equipes que disputam o campeonato sub-19 anos em Minas Gerais, e o pouco desenvolvimento do esporte no interior do estado. Tal contexto, mesmo com a boa qualidade técnica dos atletas, prejudica o processo de formação destes esportistas. Conforme registrado nesta classificação de "meaning unit" os treinadores entrevistados confirmam que este tipo de problema gera um reduzido número de jogos durante o processo de formação de atletas de basquetebol, em especial na categoria sub-19 anos.

Em Agosto de 2010 as equipes sub-19 anos não tiveram nenhum jogo no campeonato da categoria. Sub-19 é a categoria que precede o adulto e o jovem tem que estar jogando. Experiência, tempo de quadra e tudo mais. Nesta idade o número de jogos deveria ser maior até porque nesta categoria o atleta consegue suportar uma carga maior de treinamento, e a experiência adquirida nos jogos é importante para ele. Tempo de quadra, mesmo...

(T2) Número de Jogos de Basquetebol em MG.

\section{Tempo de \\ Treinamento em Horas}

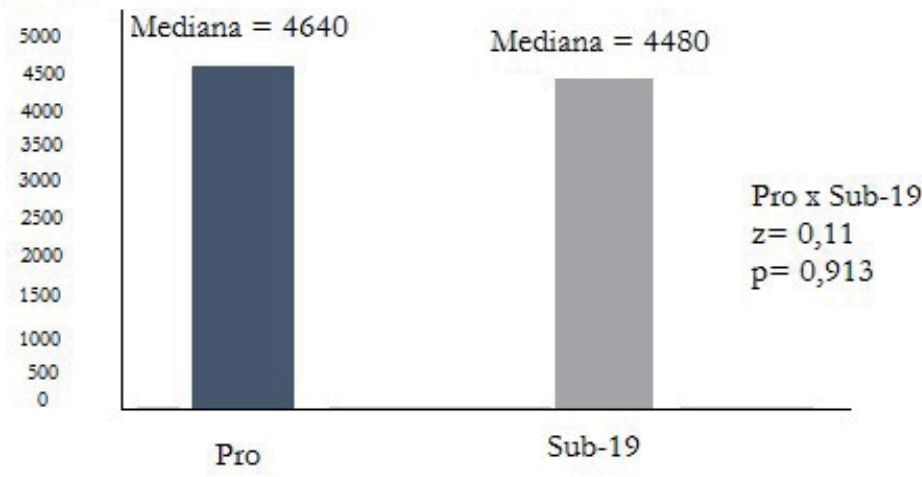

São poucos jogos por ano. As equipes da base precisam jogar... Como manter jogadores de fora no sub-19 anos se o campeonato é defasado? A federação não fomenta o esporte, e como vou manter os patrocinadores motivados? A categoria adulta joga a liga paulista, e se continuar assim todas as categorias de base jogarão em São Paulo...

(T4) Número de Jogos de Basquetebol em MG.

A maior dificuldade é a falta de intercâmbio (clubes em Minas Gerais). Existe um campeonato metropolitano muito aquém que já foi. No sub19 existem quatro equipes jogando o estadual, e não se tem nenhum intercâmbio com outras regióes de Minas Gerais. $\mathrm{O}$ atleta acaba indo para São Paulo para competir. (T5) Número de Jogos de Basquetebol em MG.

\section{Volume de treinamento}

Em relação a variável tempo de treinamento, ou seja, o volume em horas de treinamento durante a categoria de base, observa-se que não foram encontradas diferenças significativas entre os atletas profissionais e os atletas da categoria sub-19 anos (FIGURA 2). 
Na comparação entre as fases de desenvolvimento, somente dos seis aos 13 anos (TABELA 3), os atletas da categoria sub-19 anos de MG treinaram menos horas que os seus pares profissionais.

Cabe ressaltar que a diferença significativa encontrada na comparação apresentada pela TABELA 3 é devido ao maior número de atletas profissionais que iniciaram o treinamento do basquetebol em instituiçóes esportivas antes dos 13 anos de idade (34 indivíduos) em comparação aos atletas da categoria sub-19 (23 indivíduos), já que na comparação do volume total em horas de treinamento entre os seis e 13 anos, considerando apenas os atletas que já treinavam em uma equipe esportiva antes dos 13 anos, não houve diferença significativa (TABELA 4). Portanto também não foram encontradas diferenças nas comparaçóes por fases de desenvolvimento que revele uma defasagem no volume de treinamento na comparação entre os grupos.

TABELA 3 - Volume de treinamento em horas deatletas profissionais e da categoria sub-19 anos de Minas Gerais por fase de desenvolvimento e valores do teste de Mann-Whitney.

\begin{tabular}{lcccc}
\hline & Pro & Sub-19 & \multicolumn{2}{c}{ Prox sub19 } \\
Fase de desenvolvimento & Mediana & Mediana & $\mathbf{Z}$ & p \\
\hline 6-13 anos & 264 & 0 & $-2,269$ & ${ }^{*} 0,023$ \\
$14-15$ anos & 528 & 704 & 0,367 & 0,713 \\
$16-19$ anos & 3840 & 3520 & $-0,049$ & 0,961 \\
\hline
\end{tabular}

Pro: Atletas Profissionais;

Sub-19: Atletas da Categoria Sub-19 anos de Minas Gerais; *p $<0,05$.

TABELA 4 - Volume de treinamento em horas de atletas profissionais e da categoria sub- 19 anos de Minas Gerais por fase de desenvolvimento e valores do teste de Mann-Whitney, considerando apenas os atletas que treinaram basquetebol em cada fase.

\begin{tabular}{lcccc}
\hline & Pro & Sub-19 & \multicolumn{2}{c}{ Prox sub19 } \\
Fase de desenvolvimento & Mediana & Mediana & Z & p \\
\hline 6-13 anos & 1080 & 1008 & $-0,402$ & 0,687 \\
14-15 anos & 800 & 880 & $-1,708$ & 0,088 \\
16-19 anos & 3840 & 3520 & $-0,049$ & 0,961 \\
\hline
\end{tabular}

Pro: Atletas Profissionais; Sub-19: Atletas da Categoria Sub-19 anos de Minas Gerais.
O volume de treinamento fornecido ao atleta em Minas Gerais até os 19 anos é considerado adequado pelos treinadores, o que corrobora com os dados quantitativos descritos anteriormente. Além disso, os entrevistados relatam que o atleta mineiro apresenta boa qualidade técnica por ser exposto a um treinamento considerado adequado:

Tecnicamente o nosso jogador é bem formado, até porque treina mais do que joga. Conseguimos treinar mais o gesto técnico do jogo. Tanto que para São Paulo, saem todo ano seis a sete jogadores para os clubes de lá. Na questão do volume de treinamento, os atletas mineiros treinam tanto, na categoria de base, quanto os atletas de outros centros formadores, como Rio e São Paulo. (T1) Treinamento de Basquetebol em MG.

O atleta treina de forma adequada, e, além disso, nós temos aqui treinos extras para desenvolver algumas características individuais dos atletas, na base. Esses específicos são destinados a cada função do atleta, e são conciliados de forma a não atrapalhar o treinamento formal e os horários de estudo e descanso do atleta... O treinamento em Minas Gerais é muito bom em termos de qualidade e quantidade, não fica devendo aos outros estados. (T2) Treinamento de Basquetebol em MG. 


\section{Discussão}

O objetivo deste estudo foi analisar o processo de formação de atletas da categoria de base do basquetebol considerando o tempo de prática de treinamento e o número de jogos de atletas profissionais e atletas da categoria sub-19 anos de Minas Gerais.

Foi possível identificar que o número de jogos dos atuais atletas profissionais foi maior do que o número de jogos dos atletas da categoria sub19, durante a formação nas categorias de base. A competição é o momento em que as competências adquiridas no treinamento pelo atleta são colocadas à prova. Quanto mais competiçóes o atleta disputa, mais qualificado e experiente ele fica ${ }^{10}$. A atividade competitiva influencia positivamente o desempenho dos atletas, pois apenas nas competiçóes, na presença de adversários e de espectadores, e sentindo os estímulos externos, como o clima, a arbitragem e outros, é que o atleta é capaz de mobilizar suas reais capacidades máximas. $\mathrm{O}$ atleta treina para competir, é a forma que ele possui para testar seu nível de competência perante os adversários. Ao competir, o atleta desenvolve suas habilidades, e reage melhor às situações de pressão ${ }^{26}$. A respeito das estatísticas sobre o basquetebol, uma forma de avaliar o desempenho do atleta é observando o número de jogos e tempo de quadra que obteve durante uma temporada ou carreira ${ }^{27}$.

Contudo, os atletas da categoria sub-19 anos de Minas Gerais, durante a formação, encontraram vários problemas para obter um número adequado de jogos. Os treinadores enfatizam que há um número pequeno de equipes disputando o Campeonato Mineiro de Basquetebol. Há poucas equipes, principalmente do interior do estado, disputando campeonatos organizados pela Federação Mineira de Basketball. Em 2011 apenas cinco instituiçóes esportivas possuíam equipes da categoria sub-19 anos ${ }^{28}$. Visto este contexto, os atletas profissionais disputaram um maior número de jogos na categoria de base na comparaçấo com os atletas da categoria sub-19 anos.

Um número reduzido de jogos disputados durante o processo de formação acaba prejudicando o ingresso do atleta de basquetebol no esporte profissional. Ao refletir-se sobre este dado e os impactos que ele gera no ambiente prático, observa-se que os atletas recém profissionalizados no início de suas carreiras normalmente apresentam um nível competitivo inferior aos os atletas mais experientes. Isto gera um efeito colateral no basquetebol brasileiro que faz com que os clubes busquem em outros países atletas estrangeiros com uma maior bagagem competitiva. Cientes deste problema, uma das formas que os dirigentes da Liga Nacional de Basquetebol encontraram para minimizar os efeitos desta variável (reduzido número de jogos no processo de formação) foi implantar a Liga de Desenvolvimento, campeonato sub-22 anos, que tem como principal objetivo aumentar a experiência competitiva dos talentos em formação ${ }^{29}$. Devido aos atletas focarem cada vez mais na prática esportiva, dever-se-ia aumentar o número de jogos disputados ao passar das fases de desenvolvimento ${ }^{8-9}$. O aumento do número de competiçóes é uma das principais ferramentas para se aperfeiçoar a qualidade de formação e o desenvolvimento dos atletas.

A dedicação aos treinamentos é requisito básico para se alcançar altos níveis de desempenho ${ }^{2-3}$. $\mathrm{O}$ treinamento proporciona ao esportista uma melhor seleção de uma ação frente a um desafio. "Experts" conseguem antecipar açôes e identificar qual será a provável tomada de decisão do adversário ${ }^{30}$.

Indivíduos considerados "experts" frequentemente começam a treinar desde cedo, e superam os seus pares menos qualificados na dedicaçáo à prática ${ }^{11,13-14,16}$. Porém em Minas Gerais muitos atletas começam a treinar basquetebol após os 13 anos de idade. Os primeiros passos no esporte acontecem geralmente dos seis aos 13 anos de idade ${ }^{8-9}$. Tal situação pode gerar déficit na aprendizagem de conteúdos apropriados à iniciação esportiva do basquetebol, o que prejudica o processo de formação destes atletas. Em um estudo com nadadores medalhistas olímpicos brasileiros, o fato destes "experts" absolutos terem despendido várias horas do seu dia com o treinamento durante a categoria de base, foi um dos fatores que os diferenciavam dos demais nadadores que não atingiram tão alto nível excelência na carreira ${ }^{1}$. Achados semelhantes foram verificados em um estudo com atletas canadenses de nível internacional e regional de luta greco-romana ${ }^{7}$.

Para atletas de basquetebol, um estudo com atletas portugueses mostrou que aqueles que atingiram o profissionalismo tiveram um volume de treinamento maior em comparação aos que não atingiram tal estágio ${ }^{17}$.

Um ponto de convergência entre vários estudos que investigam o tempo de treinamento está no consenso que é o volume de treinamento é um dos principais fatores para o desenvolvimento e formação de atletas esportivos ${ }^{1,3,7,13,15}$. No presente estudo os atletas da categoria sub-19 anos treinaram um número de horas semelhante aos atletas profissionais, durante o seu período de formação nas categorias de base. 
Verificou-se também que os atletas de basquetebol do presente estudo, de ambos os grupos, treinaram por aproximadamente 4.600 horas na categoria de base. Este indicador encontra-se fora dos parâmetros estabelecidos pela literatura que sugerem que para a formação de um "expert" o volume de treinamento é de aproximadamente 10.000 horas. O que se observa é que estes atletas de basquetebol necessitam de um número maior de horas na categoria de base para conseguirem atingir o basquetebol profissional com um maior nível de excelência ${ }^{2-3}$. Uma alternativa para aumentar o número de horas de treinamento na categoria de base é estender o processo de formação até os 22, 23 anos (fase de desenvolvimento em que o atleta terminaria um curso superior), para que o atleta tenha um melhor desenvolvimento de sua "expertise" na modalidade, como acontece nos Estados Unidos.

Estudos mostram que não só a quantidade, mas também a qualidade dos treinamentos é um decisivo fator para que um atleta se torne um "expert",13. Relatos de treinadores neste estudo sugerem que os atletas mineiros são bem treinados e apresentam boa qualidade técnica. Porém eles também relatam que a diminuta quantidade de competiçóes dificulta que o atleta do basquetebol mineiro aprimore os conteúdos ensinados pelos treinadores durante os treinamentos nos jogos da modalidade.

Os estudos retrospectivos têm sido utilizados para as análises do desenvolvimento de carreiras esporti$\operatorname{vas}^{1,13-14,17}$. Entretanto uma limitaçâo deste tipo de estudo é o fato de que os questionários retrospectivos avaliam o tempo de prática em competições e no treinamento através de uma percepção subjetiva do atleta em relação ao tempo dedicado em cada fase do seu desenvolvimento esportivo.
Este estudo foi o pioneiro na quantificação do tempo de prática de treinamento e do número de jogos disputados por atletas de basquetebol brasileiro. Também oferece como principal contribuição a mensuração do volume de treinamento e do número de jogos que atletas em formação e atletas que já se profissionalizaram despenderam durante a categoria de base. Com base nestes dados será possível discutir de forma sistemática como solucionar alguns gargalos da formação de atletas neste esporte no Brasil, principalmente na questão de formar novos atletas "experts" para a modalidade.

Conclui-se que os atletas em Minas Gerais disputaram um número menor de jogos que os atletas profissionais durante o período de formação na categoria de base. Os treinadores comentam que a falta de competição dificulta o desenvolvimento dos atletas, já que a experiência esportiva é fundamental para que os atletas se sintam motivados a continuar na prática, além de contribuir para o desenvolvimento esportivo destes indivíduos. Um maior número de campeonatos deve ser constantemente oferecido pelas entidades organizadoras para aumentar a experiência competitiva dos atletas de basquetebol, principalmente após os 16 anos de idade.

Sobre o volume de treinamento em horas na categoria de base, os dados do estudo mostraram que não houve diferença significativa na comparação entre os atletas de Minas Gerais e os atletas profissionais. Ambos os grupos treinaram basquetebol por um número de horas inferior ao sugerido pela literatura até os 19 anos. Visto tal situação, estender a categoria de base do basquetebol brasileiro até os 22, 23 anos de idade poderia atenuar a falta de experiência competitiva e aumentar o tempo de treinamento dos jovens atletas de basquetebol.

\section{Abstract}

The formation of basketball players: quantification of practice time and the number of matches

The aim of this study was to analyze the process training of players of youth academy level of basketball considering the practice time of training and the number of matches of professional and Minas Gerais under-19 Brazilian basketball players. To do this we applied Practice Time Questionnaire for Basketball Athletes to the players, and semi-structured interviews to coaches. For quantitative data, Shapiro-Wilk and Mann-Whitney tests were applied for a 0.05 significance level. A data treatment of the interviews we used content analysis. The results show that there is no statistically significant difference between Minas Gerais players training time and professional players training time during youth academy level. In relation of competitive experience, significant differences were found $(p=0.003)$ that indicate a greater number of matches played by professional players during their formation time in youth academy level in comparison 
with the players of under-19 category of Minas Gerais. It is concluded that despite the practice time of training have been similar during the formation process in the youth academy level, the professional players have more number of matches played than the players of category under-19 years of Minas Gerais.

KeY WoRds: Athletes; Physical education and training; Sports; Qualitative research.

\section{Referências}

1. Ferreira RM, Penna EM, Costa VT, Moraes LC. Nadadores medalhistas olímpicos: contexto do desenvolvimento brasileiro. Motriz. 2012;18:130-42.

2. Ericsson KA, Lehmann AC. Expert and exceptional performance: evidence of maximal adaptation to task constraints. Annu Rev Psychol. 1996;47:273-305.

3. Ericsson KA, Krampe RT, Tesch-Romer C. The role of deliberate practice in the acquisition of expert performance. Psychol Rev. 1993;100:363-406.

4. Ericsson KA, Charness N. Expert performance: its structure and acquisition. Am Psychol. 1994;49:25-47.

5. Ericsson KA, Ward P. Capturing the naturally occurring superior performance of experts in the laboratory: toward a science of expert and exceptional performance. Curr Dir Psychol Sci. 2007;16:346-50.

6. Ericsson KA. Memory skill. Can J Psychol. 1995; 39:188-231.

7. Starkes JL, Deakin JM, Allard F, Hodges NJ, Hayes A. Deliberate practice in sports: what is anyway? In: Ericsson KA, organizers. The road to excellence: the acquisition in the arts and sciences, sports and games. Mahwah: Laurence Erlbaum Associates; 1996. p.81-106.

8. Bloom BS. Developing talent in young people. New York: Ballentine; 1985.

9. Côté J. The influence of the family in the development of talent in sport. Sport Psychol. 1999;13:395-417.

10. Côté J, Baker J, Abernethy B. From play to practice: a developmental framework for the acquisition of expertise in team sports. In: Ericsson KA, Starkes JS, organizers. Expert performance in sports: advances in research on sport expertise. Champaign: Human Kinetics; 2003. p.89-114.

11. Helsen WF, Starkes JL, Hodges NJ. Team sports and the theory of deliberate practice. J Sport Exerc Psychol. 1998;20: 12-34.

12. Helsen WF, Hodges NJ, Van Winckel J, Starkes JL. The roles of talent, physical precocity and practice in the development of soccer expertise. J Sports Sci. 2000;18:727-36.

13. Johnson MB, Castillo Y, Sacks DN, Cavacos JR, Edmonds WA, Tenebaum G. Hard work beats talent until talent decides to work hard: coaches' perspectives regarding differentiating elite and non-elite swimmers. Int J Sports Sci Coach. 2008;3:417-30.

14. Serrano JM, Santos SD, Sampaio AJ, Leite NM. Iniciação desportiva, actividades prévias e especialização no treino de futsal em Portugal. Motriz. 2013;19:p.99-113.

15. Côté J, Salmela JH, Tudel P, Baria A, Russel S. The coaching model: a grounded assessment of expert gymnastic coaches' knowledge. J Sport Exerc Psychol. 1995;17:1-17.

16. Durand-Bush N, Salmela JH. The development and maintenance of expert athletic performance: perceptions of world and Olympic champions. J Appl Sports Psychol. 2002;14:154-71.

17. Nuno MC, Leite NM, Sampaio AJ. Long-term athletic development across different age groups and gender from portuguese basketball players. Int J Sports Sci Coach. 2012;7:284-300.

18. Reis CP, Moraes LC, Ferreira MC, Noce F, Costa VT. Recursos humanos, financeiros e materiais de atletas de basquetebol nas categorias de base e a percepção dos treinadores sobre a formação dos atletas. Rev Bras Educ Fís Esporte. 2014;28:491-503.

19. Thomas JR, Nelson JK, Silverman SJ. Métodos de pesquisa em atividade física. 5a ed. Porto Alegre: Artmed; 2007.

20. Moran-Ellis J, Alexander VD, Cronin A et al. Triangulation and integration: processes, claims and implications. Qual Res. 2006;6:45-59.

21. Côté J, Ericsson KA, Law MP. Tracing the development of athletes using retrospective interview methods: a proposed interview and validation procedure for reported information. J Appl Sport Psychol. 2005;17:1-19.

22. Patton MQ. Qualitative evaluation methods. 3a ed. Thousand Oaks: Sage; 2002.

23. Urbina S. Fundamentos da testagem psicológica. Porto Alegre: Artmed; 2007.

24. Maciel LH, Moraes LC. Investigaçáo da expertise de treinadores de ginástica aeróbica brasileiros usando análise de protocolo. Rev Iberoam Psicol Ejerc Deporte. 2008;3:241-58. 
25. Tesch R. Qualitative research: analysis types and software tools. New York: Falmer; 1990. p.330.

26. Schulrz R, Musa D, Staszewski J, Siegler RS. The relationship between age and major league baseball performance: implications for development. Psycol Aging. 1994;274-386.

27. NBA. National Basketball Association. Player index. New York: NBA; 2014 [cited 2014 Nov. 2]. Available from: http://stats.nba.com/players/?ls=iref:nba:gnav.

28. FMB. Federaçấo Mineira de Basketball. Campeonatos. Belo Horizonte: FMB; 2013 [citado 23 maio 2013]. Disponível em: http://www.basketmg.com.br/default.aspx?s=19.

29. NBB. Liga Nacional de Basquetebol. Liga de desenvolvimento do basquete. São Paulo: NBB; 2013 [citado 23 maio 2013]. Disponível em: http://lnb.com.br/noticias/categorias/ldb.

30. Starkes JL. The magic and the science of sport expertise: introduction to sport expertise research and this volume. In: Ericsson KA, Starkes JL, organizers. Expert performance in sports: advances in research of sports expertise. Champaign: Human Kinetics; 2003. p.3-16.

\section{ANEXO 1 - Questionário sobre o Tempo de Prática para Atletas de Basquetebol (QTP-Basq).}

Este questionário tem como objetivo verificar o tempo de treinamento de atletas de basquetebol na categoria de base. Por favor, leia cada questão cuidadosamente e responda da melhor forma possível. É de extrema importância que todas as questôes sejam respondidas.

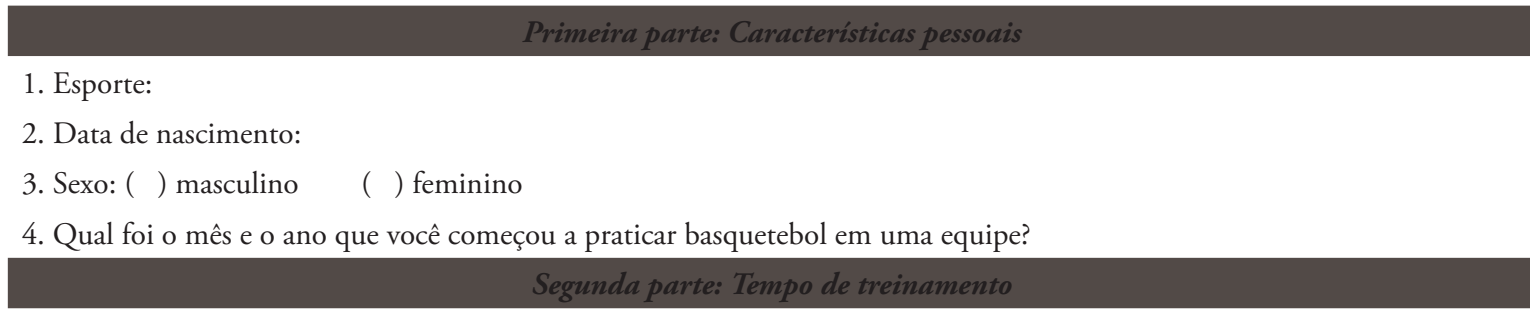

1. Qual é ou era a frequência semanal, ou seja, quantos dias na semana você treinava ou treina basquetebol em uma equipe por semana, para cada faixa etária ou fase da carreira?

\begin{tabular}{|l|l|l|}
\hline $6-13$ anos & $13-15$ anos & $15-19$ anos \\
\hline & & \\
\hline
\end{tabular}

2. Quanto tempo em média, por dia, você se dedicava ao treinamento de basquetebol para cada faixa etária ou fase da carreira?

\begin{tabular}{|l|l|r|}
\hline $6-13$ anos & $13-15$ anos & $15-19$ anos \\
\hline & & \\
\hline
\end{tabular}

3. Quantos meses por ano, você não treina ou treinava basquetebol em uma equipe?

Ou seja, quanto tempo dura ou duravam suas férias esportivas, para cada faixa etária ou fase da carreira?

\begin{tabular}{|l|l|l|}
\hline $6-13$ anos & $13-15$ anos & $15-19$ anos \\
\hline & & \\
\hline
\end{tabular}

4. Quantos jogos oficiais você disputa ou disputou por ano, de acordo com cada faixa etária ou fase da carreira?

\begin{tabular}{|l|l|l|}
\hline $6-13$ anos & $13-15$ anos & $15-19$ anos \\
\hline & & \\
\hline
\end{tabular}

\section{Muito Obrigado!}

ENDEREÇO

Varley Teoldo da Costa

Escola de Educação Física, Fisioterapia e Terapia Ocupacional Universidade Federal de Minas Gerais Av. Pres. Antônio Carlos, 6627

31270-901 - Belo Horizonte - MG - BRASIL e-mail: vtcosta@hotmail.com
Recebido para publicação: 04/ 08/2013

1a. revisão: 17/ 06/2014

2a. revisão: $27 / 11 / 2014$

3a. revisão: 27/01/2015

Aceito: 05/ 05/2015 